\title{
EDITORIAL
}

\section{Making cities for people. Moulding urban design around human beings} Helle Søholt

Gehl, Denmark

helle@gehlpeople.com

An interview by Luisa Bravo and Mirko Guaralda, on the 2nd of June, 2017

HS - Helle Søholt | LB - Luisa Bravo | MG - Mirko Guaralda

$Q$ (I). Gehl Architects is a leading international firm on urban design and public space and a paramount source of knowledge for scholars and professionals all over the world. The practice's mind-set and whole methodology are built around people and public life, why are you so passionate about this approach?

HS. We, as a practice, have an approach that is very much based on a reaction to the fact that people and public life are generally not taken into account when planning cities. Today, planners and architects have developed an expertise with a focus on the physical aspect of our environment, as well as the economic and environmental aspects, but very often life, and you could actually say essentially the client, understood as the people living in the cities, comes as an afterthought. So, the ways in which planning institutions have often approached cities haven't adequately taken fundamental social factors into account. I think that this is important because we are at a paradigm shift in planning right now; there are so many changes happening in our environment and society that we now need to deal with as designers. There is a climate crisis, we have just seen that President Trump has taken the United States of America out of the Paris agreement. Yet, we undoubtedly have serious climate issues that we need to deal with. We also have a transportation issue, where the number of trips taken in our urban areas is growing and growing. On top of this, we have issues with terrorism and growing insecurity in cities. The number and complexity of crises or risks are growing in our society and there are so many things that we need to address and deal with. If we do not consider the social issues when planning for our future, I think we are going to face a real risk of social cry-out or social unrest in many of our cities. We need to engage with people in the design process and consider the public-life aspects when planning. That is why I think it is so critical and so important to engage people; it's not something that we can do as an afterthought.

The situation is becoming critical for us as a society and I think this is something that we need to understand as planners, as architects, as landscape architects and in fact within the design field as a whole. We also need to be better at building bridges, so to speak, with experts in other fields, for example social scientists. Moreover, we need to find ways of addressing this at the highest political level. When we work in cities we often find ourselves crossing various levels of scale in terms of political management, strategies and 
visions, but we also find ourselves dealing with various traditional silos that are often found within city government. We also need to find ways to engage people locally, at ground level, in the actual implementation of projects. An approach in which we try to visualise, through our methods, how people will react to various proposals, in order to find political arguments to scale up initiatives in the public realm and create far greater programmes of initiatives in cities. So, in that sense you could say that we work on these risks and these issues at all levels of scale in cities.

MG. This is a good argument, which actually leads into the second question that we have prepared. Our second question is more about your international experience. Clearly every context is different but being an expert on public space means that you work all over the world.

$Q$ (2). Gehl works internationally, both at the academic and professional level. Based on your experiences what are the most commonly shared values on public space and quality of life among cultures and societies and what are the foremost discussions that divide opinion?

HS. The discussion of values is different from the risks we have just talked about. Public space is like a glue that enables society to be together. Essentially it's what we have in common, it's the space that we share. We see very clearly in societies that do not have a shared public realm how this absence has an impact in terms of lack of social coherence, and you could also say, connectedness. My first experience of this was when I started the company at 28 and I was probably very young and naïve at the time but I remember very clearly the first time I went to Cape Town in South Africa to lead a public realm strategy and plan for the city. I was someone coming from Scandinavia, a woman used to being able to cycle around my own town, living a comfortable life, having access to jobs, recreation, education and the means to satisfying my daily needs, all of this facilitated by a safe and accessible public realm. Now I had to face a completely different and challenging situation. My personal experience of public space back then was something that was basically not possible for some time under the apartheid in South Africa and going to facilitate a strategy for public realm development for Cape Town became a sheer eye opener for me, in terms of understanding what a great impact it has on a society when you do not have that public realm. In addition, I gained an understanding of the social and economic divide you might have if you cannot meet in public in greater groups and if you do not share that notion of common ground. And I think we still see it in many ways in cities where the lack of connectivity and the lack of public realm is impacting our quality of life and it can lead to social segregation of people; it is very clear when we see areas that are socially deprived and those areas usually have poor public spaces, lack of connections or bad connectivity and lack of transport options and so forth. Public space as a value is about supporting the shared notions in society that enable personal development as well as a collective notion of quality of life in cities. I think Bruce Mau said that citizenship is about contributing to something shared in order to gain as an individual, we could say the same thing about the public realm: it is something we contribute to collectively in order to gain as individuals.

MG. That's inspiring.

LB. Yes that's very interesting, exactly, but in the second question we also mentioned discussions that divide opinion, what you just said is really strong but do you think that many people would agree or disagree on what you just said? 
HS. I think that more people understand these issues now than when I started Gehl 17 years ago, so I do think we are building up a movement of awareness. This is not only because there are more and more architects and planners that are speaking up about people; but it's also because more and more cities understand that the traditional way of planning is no longer possible. We cannot masterplan cities in the same way as we did in the past, when we could draw a plan, then we could just implement that plan and the world would be the same 10 years later. It's not that easy anymore. Planning has become a matter of managing cities more strategically and rather than having a masterplan, we need to think about a framework within a paradigm that can allow more flexibility, then we can easily adapt to the changes that are happening. So, in that sense I do feel that more and more people understand that in order to make cities resilient, we need to include a people perspective in it. When we boil it down, resilience and adaptation are essentially about human nature and human behaviour; we as humans can adapt to the various changes that are happening to our physical environment. The people perspective and the behavioural aspect need to be part of the way we plan and design our cities moving forward.

When we look at high level research institutions or even at the European commission and other greater organisations that are working with a more overriding systemic change, we can see that even those types of institutions are starting to realise that they can only evolve by understanding human nature and behavioural changes, and this realisation is positively impacting our field. I think public realm implementers, planners and architects are becoming part of that overall trend and leading change.



Figure I (left). In 2012, "Life Between Buildings" was invited to join the 'New Nordic Architecture' exhibition at Louisiana Museum of Modern Art in Humlebæk, Denmark, and was then chosen as the museum's traveling exhibition for the Venice Biennale of Architecture.

LB. Yes and this is also the introduction to question 3 related to the film "Life Between Buildings", did you show the same exhibition and film anywhere else apart from at the Venice Biennale and the Louisiana Museum of Modern Art?

HS. We have also shown the "Life Between Buildings" big circle exhibition at IKEA's museum in Sweden. With this exhibition, we wanted to create a space and a feeling that 
was more dynamic instead of just watching panels or looking at models from a certain distance. We wanted to create a feeling of being surrounded and engaged in a new way, whilst at the same time building a classic form such as the circle.

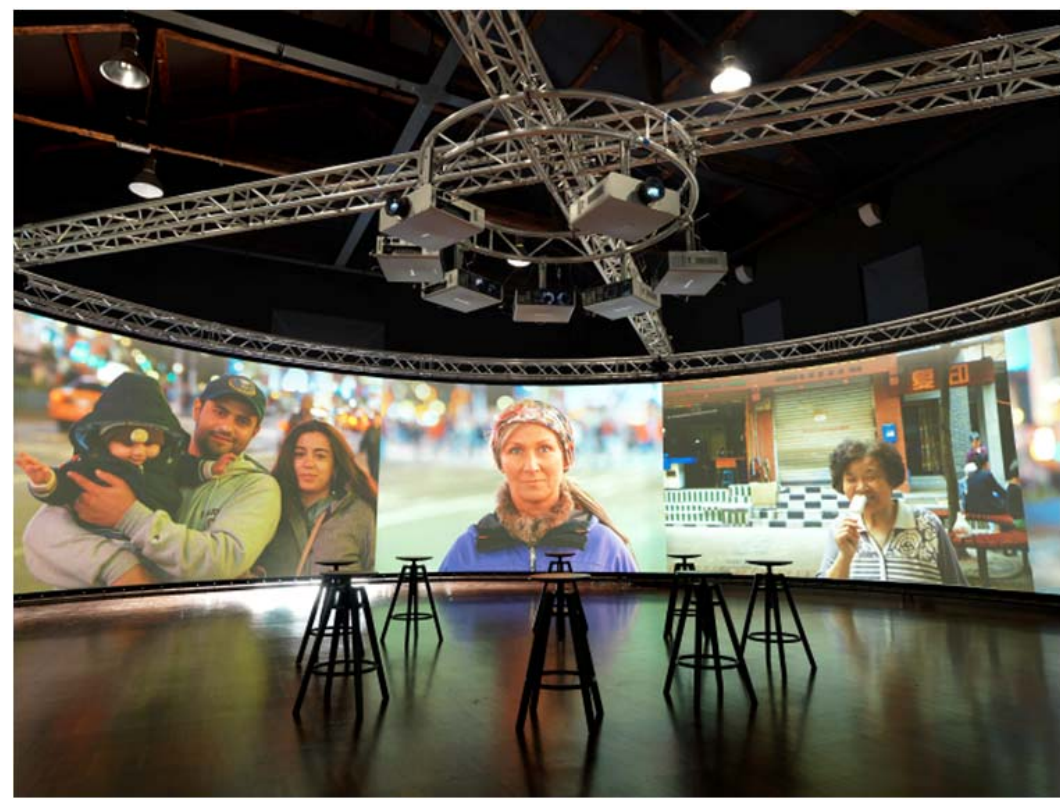

Figure 2 (right). "Life Between Buildings" is a circular, immersive, and filmic exhibition which showcases the classic Gehl principles about the human scale, senses, and how we interact with the built environment.

$Q$ (3). In 2012 the director Andreas Dalsgaard launched the film 'The Human Scale' at the Venice Architecture Biennale, as part of the 'Life between buildings' exhibition previously shown at the Louisiana Museum of Modern Art. That was an important achievement in defining public life as a fundamental concept across different contexts and cultures, to be considered as key for all future design interventions. Do you think we are in great need of an all-encompassing global vision to understand how to make cities for people? If so, how can we effectively and sensitively put a global vision into practice at the local level?

HS. When we talk about public life I think it's about a movement but it's also about activities. It's about understanding both very specific needs in a specific context, but it can also be a route to explaining some of the more shared biological needs that people have. I think that Jan Gehl has always been good at addressing some of those behavioural aspects that we all share and that human nature seems to be very fond of things that are easy: things that are very direct, everything that feels safe, things that are attentive to our senses, that we can smell, hear and touch and those are things that we share regardless of which culture we are in. I think that's one very important aspect to think about in relation to public life but then there are of course all the culturally specific elements that differ but are still related. When we studied public life in America a lot of people understood it as related to social rights, equity, and possibilities for accessing various assets in the city and I think those aspects are culturally different in various parts of the world. When we work in South America and the Global South, safety is a very important aspect, as is equity and transparency, so it is evident that these kinds of values also relate to public life: if you can access knowledge about your own neighbourhood and community and what is going on in the city, that very quickly leads to participation and engagement. So, all of these elements, 
aspects and themes are the types of values which I would consider as being widely fundamental within the realm of public life and as such also for a people-first focus on design.

LB. Indeed, we could agree on some general principles related to public space but the main effort is to put all those principles into practice when we design and when we work with public policy makers and people and citizens. I think one of the most difficult things to develop is to establish a common language for all, we need to talk the same language and have the same aims and general understanding and consensus of what that specific space could become. There is a lot of theoretical knowledge on public space but we now need to take action. This need was clearly stated at the UN Habitat III conference in Quito last year, the fact that now we need to start to take action on what we have learnt from study, best practice scenarios and theory. But for those who are actually planning cities and working on public space how can they successfully put this theoretical knowledge into practice?

HS. Well we try in our office to develop some super easy methods that we can promote and that everyone can share; we often refer to our methodology as Life, Space, Buildings and we try to promote that in Italy or in Australia, or wherever. Any project you would undertake in a city has to consider these elements in this order: Life, Space, Buildings. There are often a lot of things that are not addressed in the scope of the project, for example: what the building is supposed to give back to the city, who is going to use it, how are people supposed to arrive there, what kind of activities are going to take place there and so forth. It is probably easy to understand, I think, and easy to say but it's not always easy to implement, as you said. But we try to summarise a complete holistic approach to design in Life, Space, Buildings. Often there is too much focus on the buildings or alternatively on transport, space comes afterwards when you start looking at the configuration of buildings and the public life component is something that you might not even consider before it's too late and then it becomes an afterthought. So, trying to revert that traditional process of considering buildings and then spaces and then perhaps no life we say instead; life first, then spaces and then buildings. We try to look at how the city could do this from a city management perspective and not only a design perspective and we try to promote a more iterative process that we often refer to as Measure, Test, Refine. It's about cities testing, doing things in the public realm and engaging people around real projects instead of asking people to turn up to meetings and imagine what is possible. You can do an experiment in a city, close a street for traffic for a weekend and see what happens. Close Broadway for traffic and see what types of activities take place, go out and measure, speak with people, interview them, and then try to measure the impact the intervention has on: traffic, the climate, Co2 reductions, the economy, social relations between people and social mixing across various cultures within society and so forth. If you can see what's happening you can make people visible in that decision-making process, then you can go back and revisit your design, make it better and scale up the paths that work well and then perhaps it becomes a city wide programme. That was exactly what we did in New York, Sao Paolo, Denver and many other places. Conducting this more intuitive process-orientated approach to development by testing and engaging with people through their physical environments and their neighbourhoods and the communities they're in, allowing them, to vote with their feet instead of traditionally only being able to express their opinion by either demonstrating or participating in a traditional public event. 

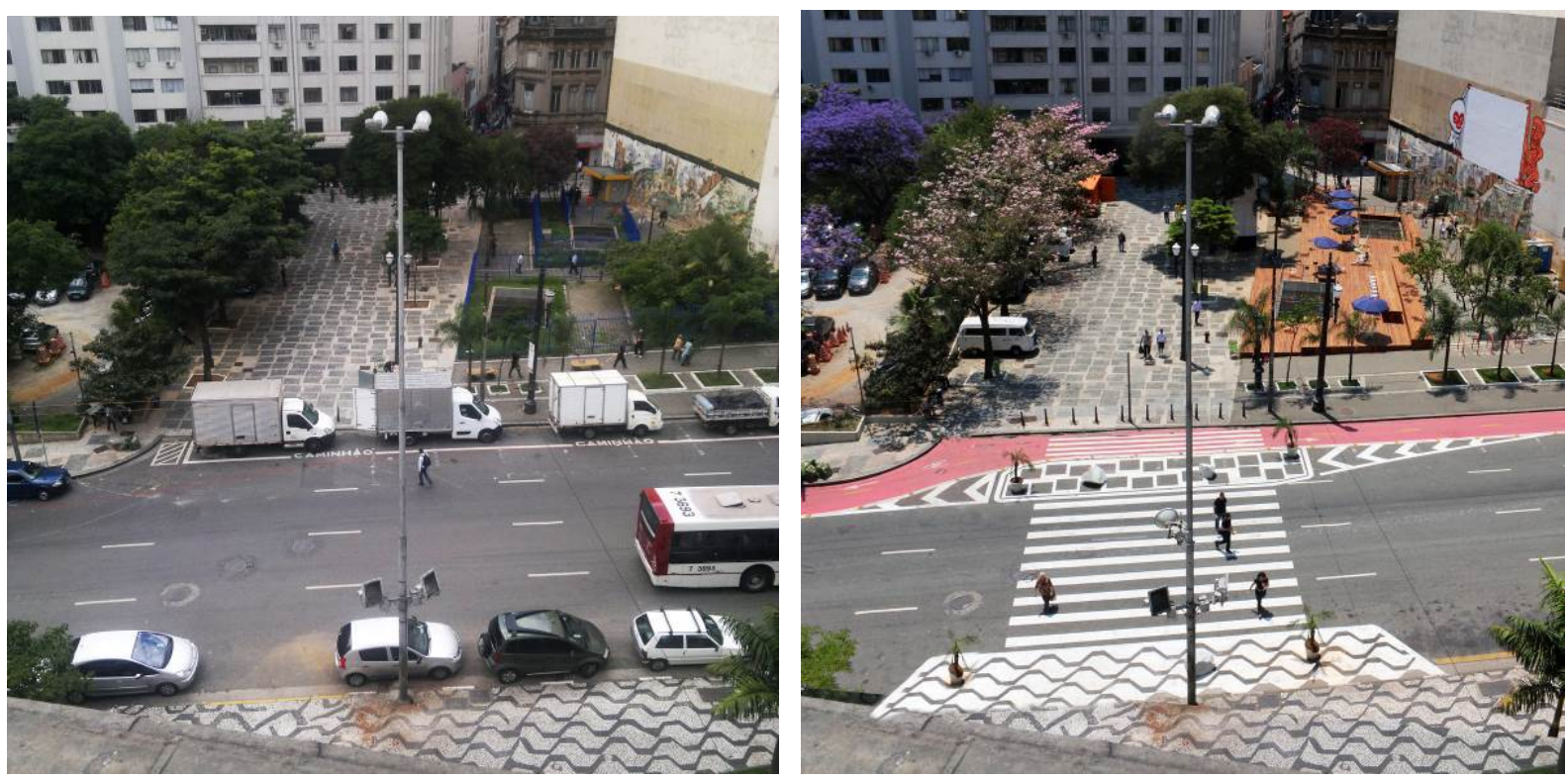

Figure 3 (left). Based on Gehl's recommendations, the Municipality of São Paulo implemented pilot projects across the city, followed by in depth surveying and citizen statements. One project was to reconnect two plazas, São

Francisco and Praça Ouvidor Pacheco e Silva, in order to create a unified public space and ensure safe pedestrian crossings across the road. This is before the pilot project.

Figure 4 (right). After the plazas, São Francisco and Praça Ouvidor Pacheco e Silva, were activated, measurements were again taken to understand if the pilot project impacted the amount of pedestrian and traffic accidents, the number of diverse staying activities, the amount of new functions in the area attracting more users, if the pilot increased the sense of community and sense of place, among many more indicators.

LB. I'm living in Bologna and they recently did exactly what you just said, they now close the main streets at weekends and they have a renewed commitment to this idea of engaging citizens back in the city centre. We are doing something that somehow matches your approach, but I think that there is still something missing. When you talk about public space, there are many different stakeholders and parties involved because it's not just about urban planning, you also have traffic and the environment for example. So you have different people working on the same subject and if you're lucky they all agree on the same vision but if you're not, maybe one side is just promoting cycling as one of the main issues for the city and another is suggesting closing the streets for the weekend or for specific periods. The problem is that often those projects are running alongside one another rather than being intertwined to create a common comprehensive effort to change the city to accommodate people's needs. That's why I was saying before that we have a lot of knowledge but we need to work together to get the best results and outcomes for citizens in the city.

HS. Yes and that's where finding ways to break down some of these traditional silos that we have built up in cities is incredibly important, because the public realm is where everything comes together and we can't make a complete design or implement complete processes with transport while looking exclusively at the traffic lanes - the landscape department only considering trees and the planning, water management, the cultural and health departments focusing only on their specific areas -that kind of blinkered approach is detrimental to the whole system. That is dissecting the public realm and that's not how people experience it, they experience it as a complete environment and space; we need to find ways to accommodate a matrix collaboration around these issues and I think what you bring up Luisa is also very closely related to political leadership because I think we

6 | The Journal of Public Space, 2(2), 2017| ISSN 2206-9658

(c) Queensland University of Technology 
need new skills in the city. Earlier we had project managers that were checking that projects were implemented to the agreed budget and to the agreed time but that's not sufficient anymore. We need facilitators in the city who can facilitate a process, who understand engagement and who can balance these various views from the various departments involved as well as from the diverse users and stakeholders.

Then we need strategic decision-making and bold leaders who can learn from the implementation of these experiments and these projects, leaders who can learn how to take positions based on the acceleration of risks and problems that the city has. That's why I think we need to work differently with planning: it cannot be a fixed masterplan idea, we need to develop more strategic frameworks for cities where the people aspect is as equally important as the environmental, transportation, and densification aspects of the plan. We need a framework that both allows and enables our political decision makers to make the right and most sensible decisions at any given time. So, it is basically different people skills, decision makers are people too and we need to train them to see the different issues holistically.
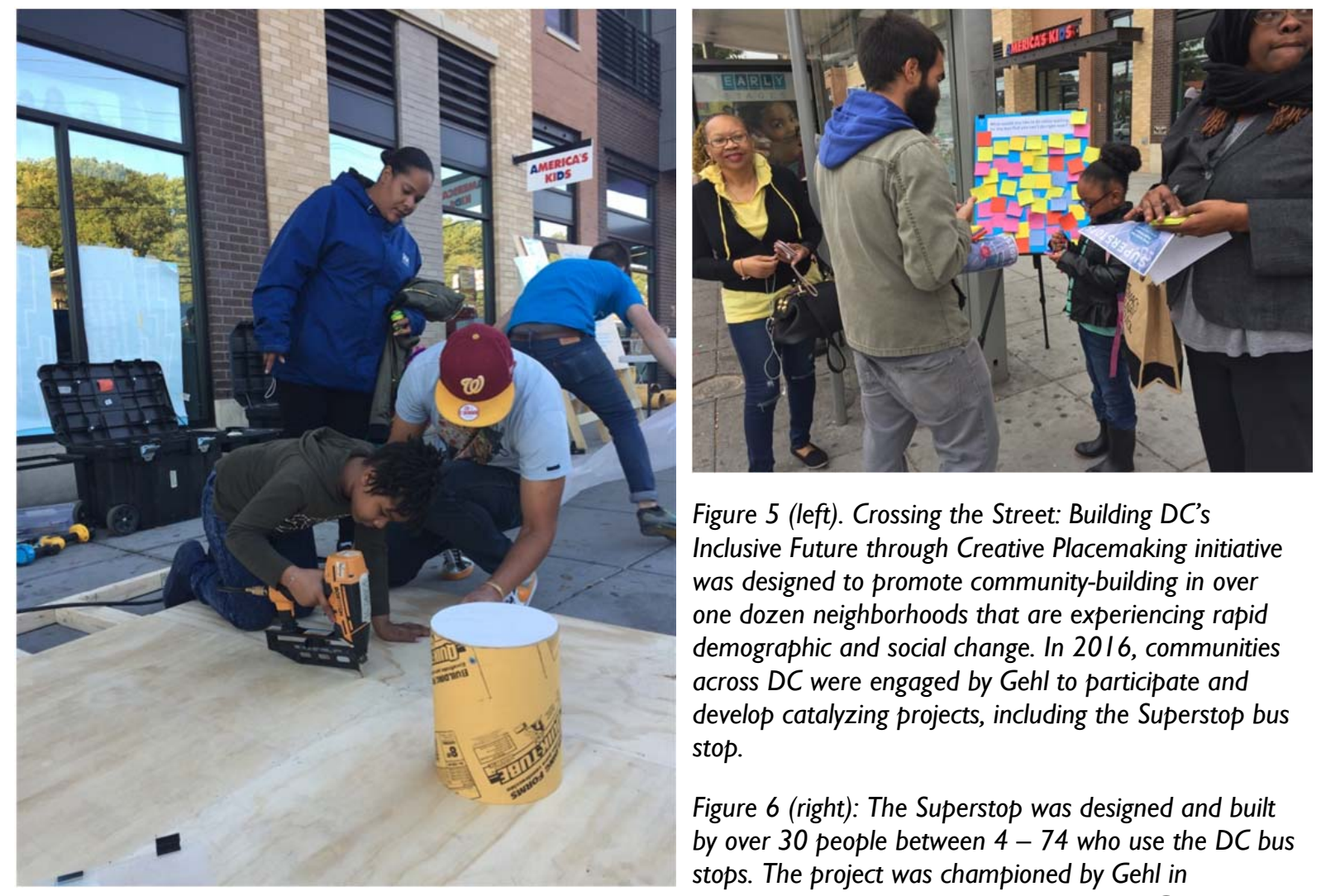

Figure 5 (left). Crossing the Street: Building DC's Inclusive Future through Creative Placemaking initiative was designed to promote community-building in over one dozen neighborhoods that are experiencing rapid demographic and social change. In 2016, communities across DC were engaged by Gehl to participate and develop catalyzing projects, including the Superstop bus stop.

Figure 6 (right): The Superstop was designed and built by over 30 people between $4-74$ who use the DC bus stops. The project was championed by Gehl in collaboration with Public Workshop, Mark Garrett and Angel Zambarano, The Hope Foundation, and Park 7 Apartments. This project was supported by The Kresge Foundation, Gehl Institute, and The Summit Foundation.

In relation to almost any project that we have in this office, we spend a lot of time changing people's minds or bringing the politicians or decision-makers and managers along, in order to give them new tools to look at these issues in a more holistic way. We have three values in our company, the first one is a very funny value, it is called the Viking principle. There was no captain on the old Viking boats because everybody was 


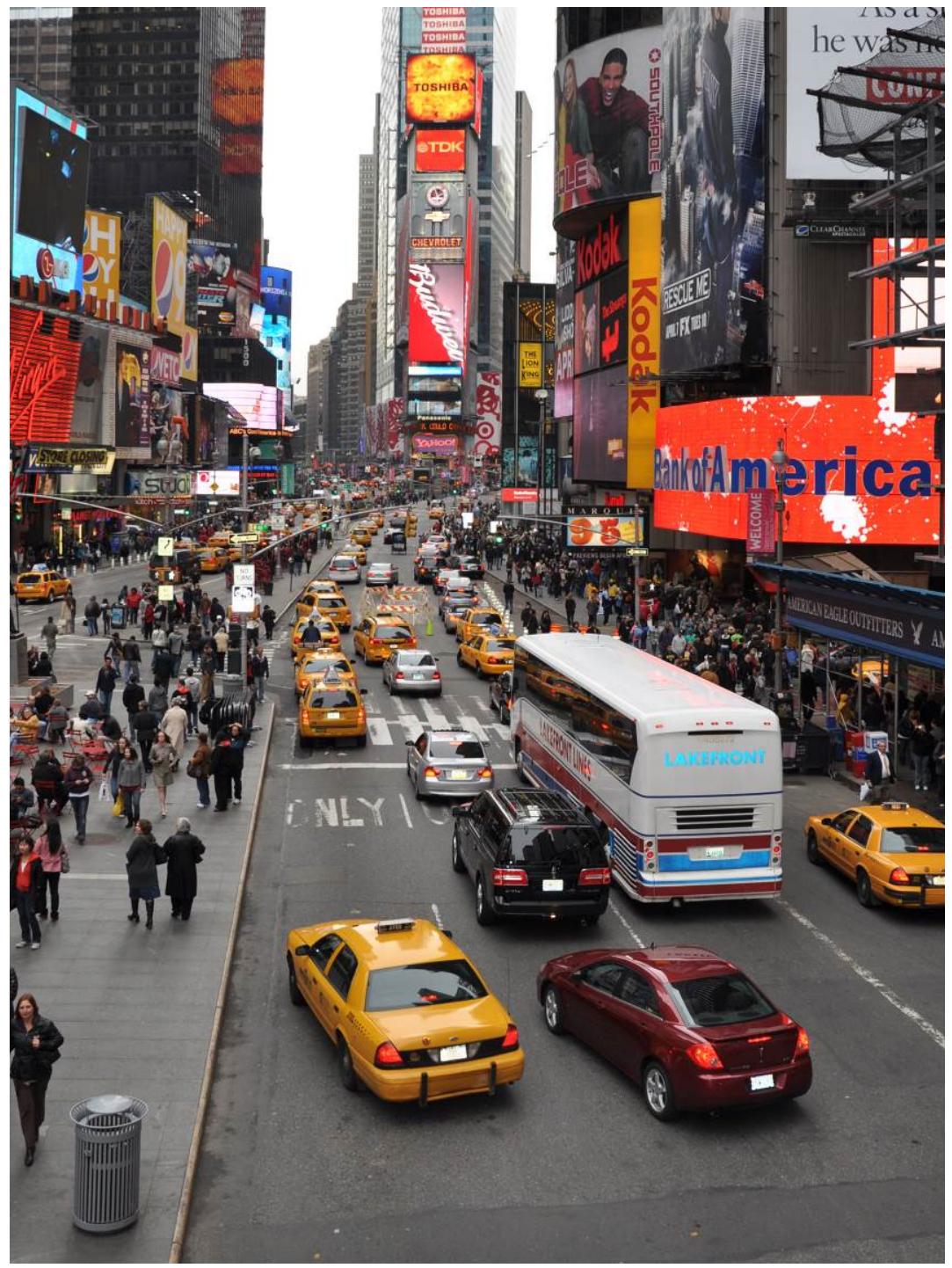

Figure 7. In 2007, Gehl was asked to conduct an analysis of Times Square's public realm, and to formulate a

strategic vision to improve the conditions for pedestrians while promoting a balance between modes of transportation. Findings showed that despite the fact that pedestrians made up $90 \%$ of the users at Times Square, only $10 \%$ of the public realm was dedicated to pedestrian use.

Photo by: NYC DOT.

rowing and I often use that metaphor to talk about our company here. I might be the founding partner and manager but l'm part of the rowing too, I work too and we also need cities to think about this idea: all the decision-makers are people too and we need to think about them as equally importantly engaged in all processes. Then we also have a second value in that we call ourselves pragmatic idealists, because as you mentioned Luisa, the world is never black and white and we will never get anything done if we sit as idealists and experts up in our ivory towers, looking down at the world and thinking that we know better that the rest of them. We will never achieve anything with a change of mindset and a change of paradigm if we don't get our hands dirty. So, we all need to let loose a little bit in a new way of planning and a new way of working. We need to let go and not plan so much, to trust citizens to make good decisions and to take co-decisions. Politicians need to get out of their ivory towers and trust meeting with citizens to make better decisions. 
Helle Søholt

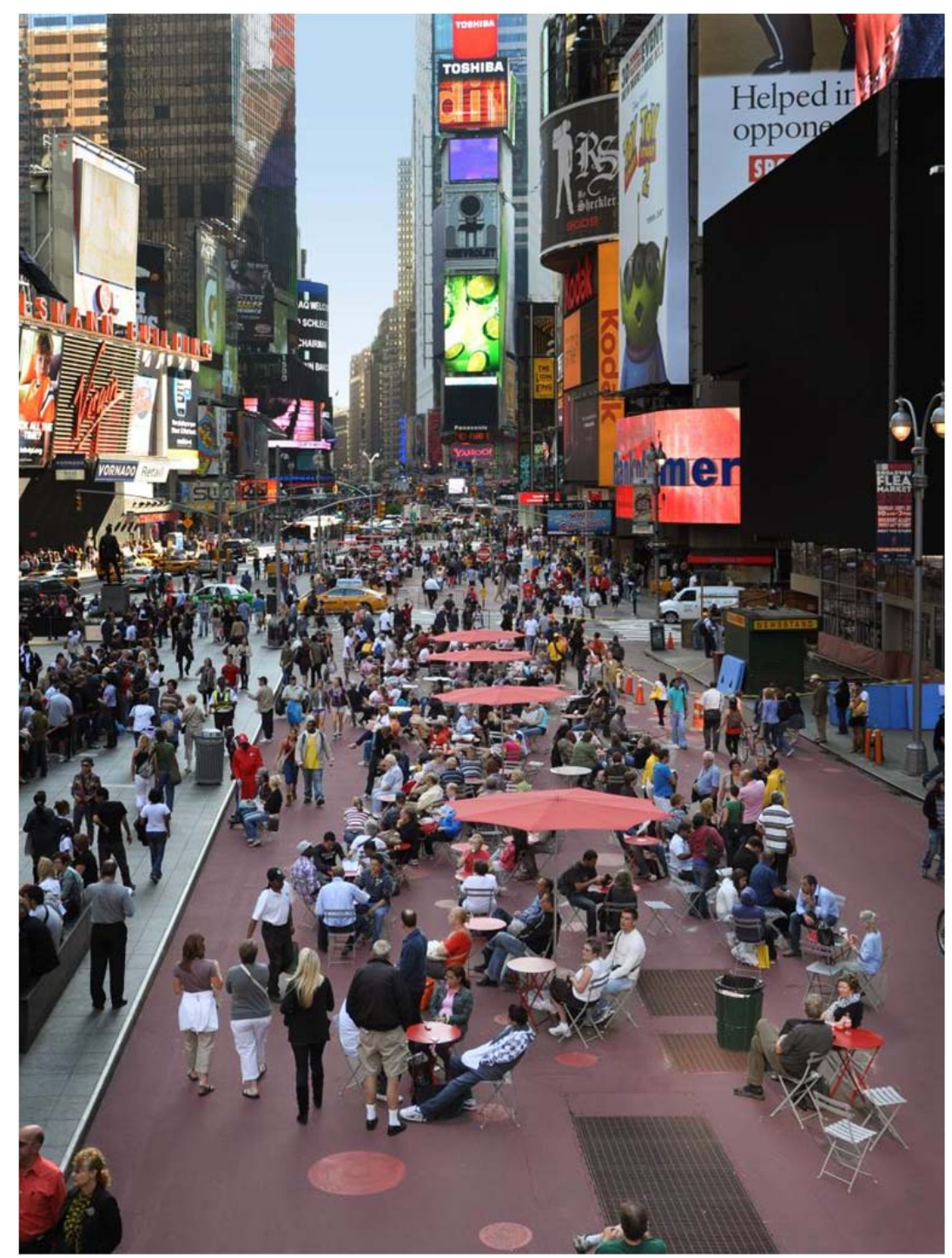

Figure 8. Between 2008 and 2009 interventions were implemented along Broadway Boulevard including Times Square, Herald and Greenly Squares and Madison Square Park, reclaiming 45,000 m2 of public space. By 2010 the project had doubled the amount of bicycle lanes in NYC, improving travel speeds for motor vehicles as well. The data showed safety increased and general satisfaction in the areas increased among residents, locals, and visitors. Photo by: NYC DOT.

So we often use that term, pragmatic idealists, in order to make sure that we can get things done. Then the last principle is of course, people first, always people first.

LB. Well that's clear from your whole philosophy and your website, making cities for people is a very clear message, I think that anyone can easily understand what you are doing there in Copenhagen.

Well the fourth question is in relation to your new offices in the United States, in New York and San Francisco: as you pointed out, when moving to the US the concept of public space changes a little bit as its more about safety, equity and civil rights. Do you think that working in the US is different from working in Europe? 
$Q$ (4). On the back of the momentum of the film 'The Human Scale', brand new Gehl offices were opened in the USA and the practice's network expanded on the global level. What do you think were the highlights of your work in the last 5 years? What is next for Gehl?

HS. It's very different. In Europe historically we have very strong planning departments, we have stronger municipal governments, we have a history of investing in the public realm and we are very proud of the public realm. You come from Italy so you know all about the pride around the civic public spaces that we have, it is definitely a proud part of our institution and cities. That's not the case in the US, we have to constantly argue why the public realm matters and why the cities need to invest in it. The cities in the US are not strong in the same way as they are in Europe, they're not financially strong either, basically in American society it's the individual before the collective and that's why a lot of our work is sponsored by foundations.

A large part of the portfolio of our work consists of collaborations between city governments and private investors or organisations like business improvement districts or foundations that want to advocate for improvement in design processes, a more equitable society or a better environment for example and we have learnt an incredible amount through working in this way through more collaborative processes.

In Europe, traditionally we have one client, we have the city as the client or we are working for a private developer for example. But in the US we are being challenged by often having two, three or four clients, so the effort is shared in that sense. It sometimes does make the actual physical changes on the ground more difficult and it does sometimes make it slower but on the other hand it is building a movement because more people are participating and that in turn has actually made us start a new initiative.

So first we opened up the two new offices in the US and then last year we started the Gehl Institute, which is a completely separate non-profit organisation with independent management and an independent board, with the focus of building a public life movement. It is now aiming to build a new mode of practice around public space, one that is evidence based and relies on different research findings as well as on best practice scenarios of building cities for people. So now our mission is to essentially create a new practice; the mission of the institute is to impact policy making and enabling this global movement of building a new way of approaching planning and design, where public life becomes the one component that is not missing.

Gehl Institute is doing this through new types of research, through advocacy work and learning activities like seminars, master classes, study trips and so forth. It's a very young and new organisation and it's very small, we still have less than 5 staff. However, it's exciting to see how we are now gaining a huge amount of interest from the health sector and we have a collaboration with the Robert Wood Johnson Foundation, one of the largest in the US.

They are interested in public life but from a health perspective. We are also getting a huge amount of interest from Knight Foundation that is leading initiatives in the states on social equity; they want to better understand how the public realm is actually supporting social mixing of people across various income levels and income groups within society. So it's exciting that in the 17 years since starting the company, I think we have been successful in terms of impacting the field of planning and the field of design. But our ambition now with Gehl Institute is to see whether we can impact other fields and other practices like social justice, the health sector and the environmental sector and so forth, 
to hopefully find new ways of working and a new type of knowledge that can support the public life focus.

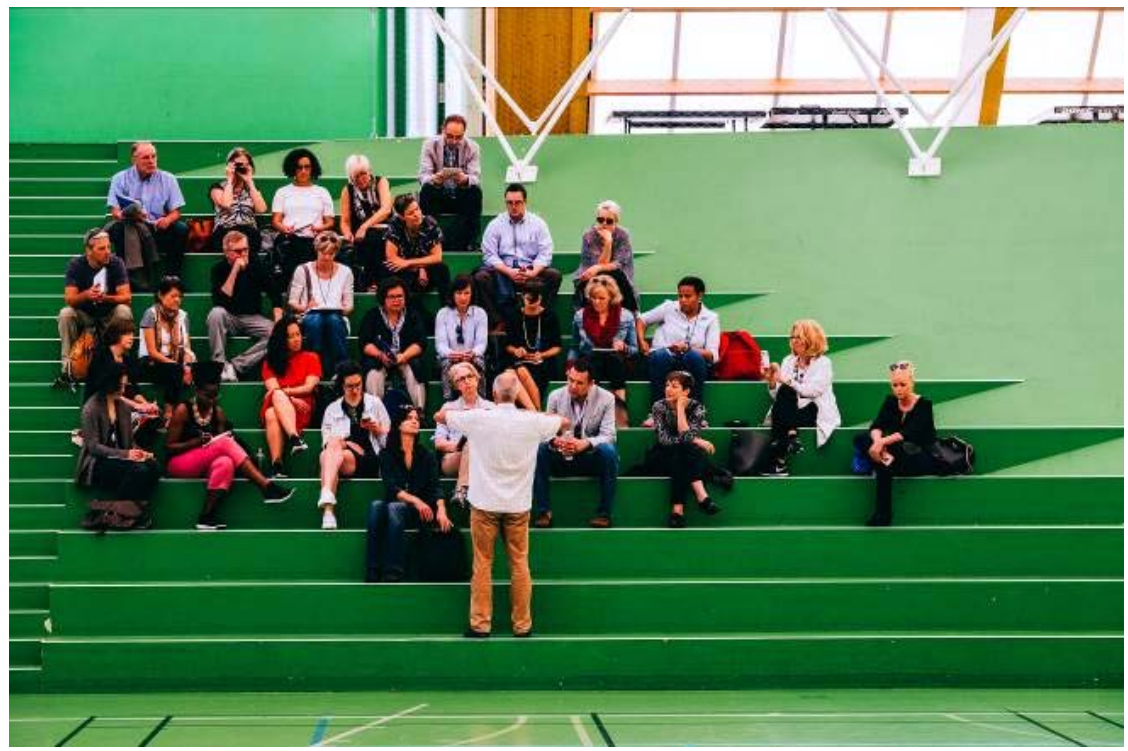

Figure 9 (left). Robert Wood Johnson Foundation, the largest health philanthropy in the U.S., visited Copenhagen in June 2017 for a three-day study tour led by Gehl Institute and Gehl, the practice to explore how public spaces contribute to individual and community health and equitable neighborhood development. Image by Boundless.

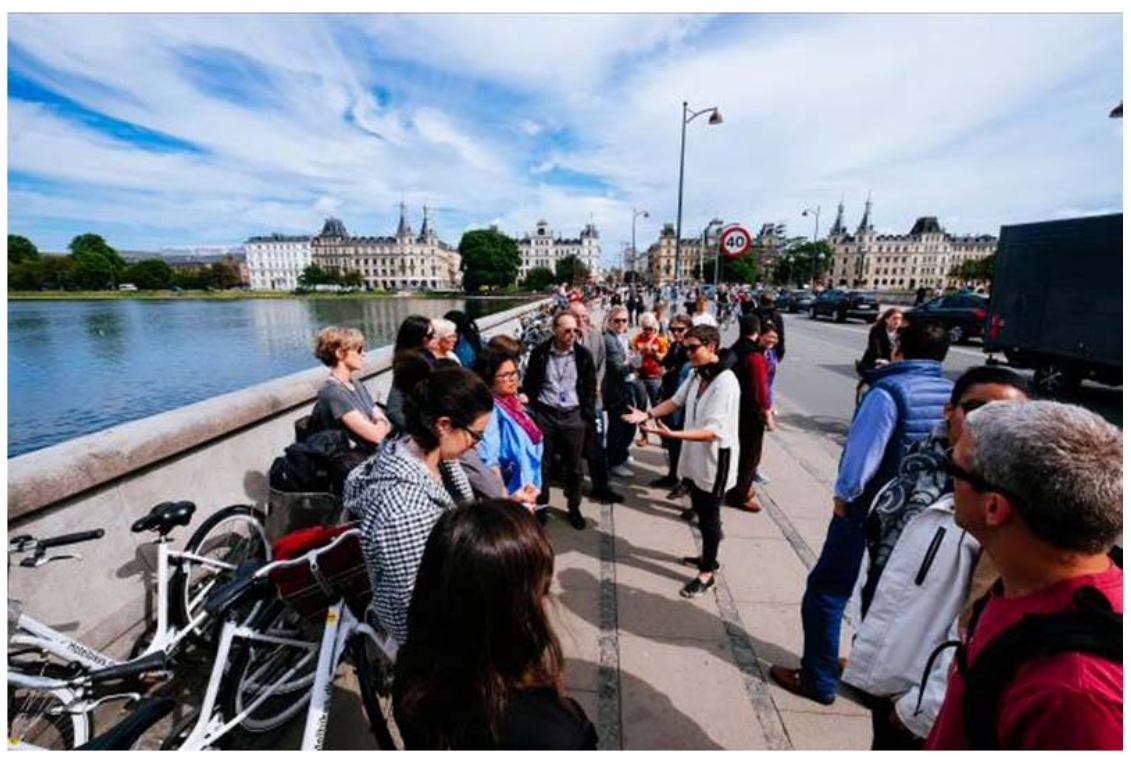

Figure 10 (right). Helle Søholt discussing the development of Copenhagen's bridges as a major public resource during the Robert Wood Johnson Foundation study tour in Copenhagen. Image by Boundless.

LB So I think you answered the fourth question, what is next for Gehl. HS Exactly.

$Q$ (5). Nowadays cities are facing global challenges, frequently related to evolving societies and diversifying multicultural environments. Public space is dealing with expanding conflicts and contradictions. With these current challenges in mind what would you like your legacy to be for future generations? 
LB. So the last question is related to global challenges, evolving societies and conflicts. Actually that's why I mentioned the Global South because although in our westernoriented mainstream of knowledge, it's true that migration is changing the face of our societies and conflicts and terrorism are now affecting safe western contexts. In other contexts such as the Middle East, where I have been working, conflicts are and have been for a long time ever-present in public space. So the last question is, with these current challenges in mind, what would you like your legacy to be for future generations in terms of a global approach to public space? Because it is already being pointed out that in the future those challenges which we in the West perceive as somewhat far away will in the very near future be more significantly affecting our urban contexts too.

HS. Well I think when we look to the future we can be sure of one thing and that is that everything will change. The one thing that has changed very slowly through thousands of years is mankind, is people. I think we need to find ways of understanding how we can bridge the ever-changing and more and more dynamic world around us with the fragile human being in the centre of all of that. I often hear that "oh technology is going to save us all" but l'm not so sure about that. There are already some signs that technology is going to create an awful lot more problems for us when it comes to autonomous vehicles for example; we can see Uber and Lyft in the USA is already creating more rather than less traffic, it's causing people to use private vehicles instead of public transport. We see freight in cities exploding and so forth. I think we need to understand and find a way for people to be at the centre of decision-making and planning. My wish for the future of the Global South is that we could leapfrog, I wish that we didn't have to make all the same mistakes in those developing countries but learn from all the mistakes we've made in western countries and learn from those in order to do better. And I worry when I see the building of humongous highways and flyovers in Bangladesh and Jakarta and other places, as a way of ensuring better mobility, because that is a way of repeating the mistakes of the past rather than actually leapfrogging and finding ways for technology to support shared trips in a smart way. I think we, as a field and as a professional practice, need to think seriously about how we can jump and achieve that leapfrog so that we are not repeating the mistakes of the western countries in the Global South. We don't have the time, we don't have the money or the spatial resources, we don't have the space to go through the same phases as we went through in the Sixties, Seventies and Eighties, we need to find new ways. So that's kind of back to where we started I guess, that's why this is important and urgent. That would be my wish for the future and for our professional field.

LB. I agree, but it's very difficult, we have to work a lot, but all together.

To cite this article:

Søholt. H. (2017). Making cities for people. Moulding urban design around human beings. The Journal of Public Space, 2(2), I-12. DOI: 10.5204/jps.v2i2. 102

This article has been accepted for publication in The Journal of Public Space.

Please see the Editorial Policies under the 'About' section of the journal website for further information.

This work is licensed under a Creative Commons Attribution - Non Commercial 4.0

International License - https://creativecommons.org/licenses/by-nc/4.0/ 